\title{
BIROKRASI DAN KORUPSI DI INDONESIA DALAM PERSPEKTIF SEJARAH (Catatan Keprihatinan Seorang Muslim)
}

Oleh:Suwarno*

\section{Abstract}

This paper aims to describe relation between corruption and bureaucracy in Indonesia by bistorical perspective. The writer explains concepts of bureaucracy, corruption, relation among bureaucracy, corruption and democracy, which then the presents corruption and bureaucracy in bistorical perspective (comparing colonial and postfreedom era in Indonesia), and opinion of the writer as a Muslim. According to the writer, corruption is not Indonesian nation's culture. The problem of corruption is related with structure of Indonesian bureaucracy softly and turns on possibility ram-

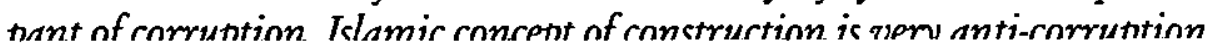

حاول الكاتب ترسيم الصلة بين جريمة ألفساد والرشوة وما في حكمها وبين طبيعة البيروقراطية التي تعمل في إندونيسيا من منظور التاريخي. واستهل الكاتب بكثه حول

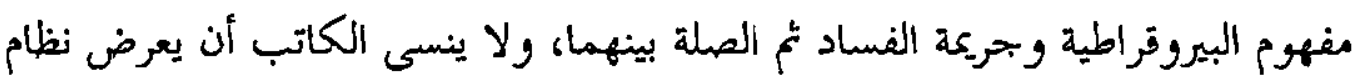
الليموقراطية وعلاقتها بالبيروقراطية وجريمة الفساد على مرور الزمان في إندو نيسياء

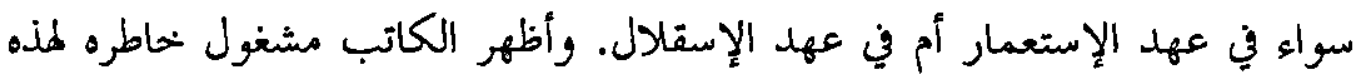
الظروف وبحيمة الفساد. إلا أن هذه البحريمة حسب رأي الكاتب لم تعد من ثقافات أبناء الوطن ولو كانت إزالتها لم تكن يسرا بسبب علاقتها الوئيقة ببنيان نظام البيروقراطي التي تسمح انتشار هذه الجريكة التي يمنعها الإسلام.

Katakunci:Indonesia, birokrasi, dan korupsi Purwokerto.

- Penulis adalah Dosen TetapProgram StudiPendidikan Sejarah FKIPUniversitasMuhammadiyah 


\section{A. Pendabuluan}

Sungguh sangat ironis, setelah 60 tahun merdeka, Indonesia masih berkutat dengan korupsi. Korupsi menjadi salah satu akar penyebab utama timbulnya krisis multidimensi sejak medio 1997 hingga sekarang belum dapat diatasi. Bahkan, mengutip survai yang dilakukan oleh lembaga The Political and Economic Risk Consultancy Ltd. (PERC) pada bulan Januari-Februari 2005 menunjukkan bahwa Indonesia berada di peringkat pertama sebagai negara terkorup di Asia. Ada dua lembaga terkorup di Indonesia yang menempati urutan pertama dan kedua, yakni peradilan dan birokrasi. ${ }^{1}$

Korupsi merupakan salah satu bentuk keserakahan yang disebabkan oleh kondisi mental yang korup dan moral yang terlepas dari ajaran agama. Menurut Buya Syafii (Ketua PP Muhammadiyah 1998-2005), keserakahan akibat korupsi, sebagai contoh berkaitan dengan kerusakan hutan (praktik penebangan hutan secara liar (illegal logging), pencurian kayu dan satwa, degradasi hutan) menampakkan diri pada dua wajah, yakni wajah uang dan wajah kekuasaan. Kedua wajah tersebut di Indonesia menyatu pada istilah "penguasaha", yakni kolusi yang terjadi antara penguasa (pejabat birokrasi) dengan pengusaha untuk keuntungan mereka sendiri. ${ }^{2}$

Kajian ini akan meneropong jalinan antara korupsi dan birokrasi di bumi Indonesia yang didekati dari perspektif sejarah sebagai catatan keprihatinan seorang Muslim. Kajian diawali dengan merunut pengertian birokrasi; korupsi; relasi antara birokrasi, korupsi dan demokrasi; birokrasi dan korupsi pada masa kolonial; birokrasi dan korupsi masa pascakemerdekaan; serta catatan keprihatinan seorang Muslim.

\section{B. Pengertian Birokrasi}

Istilah birokrasi diambil alih dari bahasa Inggris, dari kata bureaucracy. Secara etimologis, istilah tersebut berasal dari akar kata bureau yang berarti meja tulis, yakni tempat pejabat biasanya bekerja, dan ditambah kata cracy, yang bermakna aturan (rule). Tidak heran dalam kamus bahasa-bahasa Eropa abad

1 Periksa Vincentia Hanny S. (2005), "Melawan Korupsi 'Vis a Vis' Perlawanan Koruptor”, dalam Kompas, 16 Agustus, p. 45.

2 Lihat Ahmad Syafii Maarif (2005), "Indonesia Baru di Tengah Pertarungan antara Mosaik Budaya yang Elok dan Kaya dengan Ancaman Keserakahan," dalam Millah, Jumal Studi Agama, Vol. IV, No. 2, pp. 10-11. Artikel tersebut diangkat dari pidato Buya Syafii pada acara Penerimaan Anugerah Hamengku Buwono IX pada tanggal 20 Desember 2004 di Universitas Gadjah Mada Yogyakarta. 
ke-18 dan ke-19 M, istilah birokrasi diartikan sebagai kekuasaan, pengaruh, atau wewenang yang dimiliki oleh para pejabat pemerintahan. ${ }^{3}$

Dewasa ini birokrasi umumnya dipahami sebagai lembaga atau institusi yang melaksanakan fungsi-fungsi dan tanggung jawab negara. Hal ini berangkat dari pengertian bahwa birokrasi merupakan kamar mesin (the engine-room) nya negara. ${ }^{4}$ Selain itu, birokrasi juga bisa dipahami sebagai organisasi para pejabat pemerintah yang tersusun secara hirarkis dan diangkat untuk melaksanakan tujuan-tujuan publik tertentu. ${ }^{5}$

Berbagai pengertian yang berkembang mengenai birokrasi, sekurangkurangnya dapat dirangkum dalam tujuh pengertian, sebagai berikut:

1. Birokrasi sebagai organisasi yang rasional;

2. Birokrasi sebagai organisasi yang efisien;

3. Birokrasi sebagai kekuasaan yang dijalankan oleh para pejabat pemerintahan;

4. Birokrasi sebagai administrasi negara atau administrasi publik;

5. Birokrasi sebagai administrasi yang dijalankan oleh para pejabat pemerintahan;

6. Birokrasi sebagai bentuk organisasi yang memiliki ciri-ciri dan kualitas tertentu;

7. Birokrasi sebagai salah satu ciri masyarakat modern. ${ }^{6}$

Citra birokrasi yang ideal di kalangan para ilmuwan politik biasanya mengacu pada pemikiran Max Weber (1864-1920), sosiolog Jerman dan para pendukungnya yang disebut sebagai Birokrasi Weberian (Weberian Bureaucracy). Birokrasi Weberian mempunyai lima ciri pokok, yaitu: (1) adanya derajat spesialisasi atau pembagian tugas yang jelas; (2) adanya struktur kewenangan hirarkis dengan batas-batas tanggung jawab yang juga jelas; (3) hubungan antar anggota [birokrat] yang impersonal; (4) cara pengangkatan atau rekrutmen pegawai yang didasarkan pada kecakapan teknis; dan (5) adanya pemisahan antara urusan dinas dengan urusan pribadi yang akan menjamin pelaksanaan tugas secara efisien. ${ }^{7}$

${ }^{3}$ Martin Albrow (1996), "Bureaucracy" terjemahan M. Rusli Karim dan Totok Daryanto, Birokrasi, Yogyakarta: Tiara Wacana, pp. 2-3. .

+ Vincent Wright (1992), Comparative Government and Politics an Introduction, London: The Macmillan Press Ltd., p. 342.

${ }^{5}$ Eva Etzioni Halevy (1983), Bureaucracy and Democracy a Political Dilemma, London: Routledge and Kegan Paul, p. 85.

${ }^{6}$ Martin Albrow, op. cit., pp. 82-103.

${ }^{7}$ Vincent Wright, op. cit, pp. 342-343; bandingkan dengan Moeljarto Tjokrowinoto, (1995), Politik Pembangunan Sebuab Analisis, Arah, dan Strategi, Yogyakarta: Tiara Wacana, p. 62. 


\section{Pengertian Korupsi}

Istilah korupsi, sama seperti birokrasi, diambil alih dari bahasa Inggris, dari kata corruption. Kata corruption merupakan kata benda yang tak dapat dihitung (uncountable noun), yang bermakna menjadi korup, rusak atau busuk.. Asal kata corruption ialah dari kata sifat corrupt, yang berarti: korup, jahat, buruk, atau rusak. Corrupt yang dipakai untuk kata kerja bermakna: menyuap, merusak atau mengubah. ${ }^{9}$

Makna korupsi yang diaplikasikan dalam bidang politik atau kekuasaan umumnya merujuk pada dalil yang dikemukakan oleh ilmuwan politik Inggris, Lord Acton. Tokoh ini pernah membuat sebuah pernyataan yang sangat terkenal dan kini menjadi sebuah dalil yang diyakini mendekati benar, "power tends to corrupt and absolute pozver corrupts absolutely" (kekuasaan itu cenderung korup, dan kekuasaan yang absolut akan korup secara absolut pula). ${ }^{10} \mathrm{Hal}$ ini berarti bahwa kekuasaan menjadi sumber utama terjadinya korupsi, serta rawan timbulnya penyimpangan dan penyalahgunaan yang merugikan kepentingan seluruh rakyat.

Mengutip Amien Rais, terdapat empat jenis korupsi, yaitu: (1) korupsi eksortif; (2) korupsi manipulatif; (3) korupsi nepotistik; dan (4) korupsi subversif. Pertama, korupsi eksortif mengacu pada keadaan yang membuat seseorang terpaksa menyogok agar dapat memperoleh sesuatu atau mendapatkan perlindungan atas hak-hak dan kebutuhannya. Contoh, seorang pengusaha yang terpaksa memberikan sogokan kepada pejabat tertentu agar mendapat izin usaha dan mendapat perlindungan terhadap usahanya.

Kedua, korupsi manipulatif mengacu pada usaha kotor yang dilakukan oleh seseorang untuk mempengaruhi pembuatan kebijakan atau keputusan pemerintah demi keuntungan pribadi yang sebesar-besarnya. Misal, seseorang atau sekelompok pengusaha memberi uang kepada bupati, gubernur, mentri atau anggota dewan (DPR atau DPRD) agar menyusun peraturan yang menguntungkan mereka.

Ketiga, korupsi nepotistik mengacu pada perlakuan istimewa yang diberikan pada anak-anak, kemenakan atau saudara dekat para pejabat dalam setiap eselon di manapun mereka menjabat.

${ }^{8}$ Periksa A.S. Hornby (1978), Oxford Advanced Leamer's Dictionary of Current English, Oxford: Oxford University Press, p. 193.

${ }^{9}$ Lihat John M. Echols dan Hassan Shadily (1987), Kamus Inggnis-Indonesia, Jakarta: Gramedia, p. 149.

${ }^{10}$ Djoko Susilo (editor) (2004), Kuasa antara Moral, Etika dan Amanat: Percikan Pemikiran M. Amien Rais, Yogyakarta: Palem, p. 5. 
Keempat, korupsi subversif mengacu pada pencurian terhadap kekayaan negara, biasanya dilakukan oleh pejabat yang berkolusi dengan pengusaha. Korupsi semacam ini bersifat subversif karena membahayakan eksistensi negara dalam jangka panjang. ${ }^{11}$

\section{Relasi Birokrasi, Korupsi dan Demokrasi}

Mengacu pada teori liberal tentang negara, birokrasi sebenarnya berada pada posisi berseberangan dan bahkan bertentangan dengan demokrasi yang memiliki hubungan sangat erat dengan kapitalisme. Secara politis, birokrasi sebagai pemerintahan atau kekuasaan oleh para pejabat yang diangkat jelas berada dalam posisi berlawanan dengan demokrasi sebagai pemerintahan atau kekuasaan oleh rakyat melalui wakil-wakil mereka yang dipilih. Hak-hak politik dan kebebasan yang melekat (inherent) dalam demokrasi diyakini berasal dari kebebasan ekonomi (kapitalisme). Demokrasi hanya dapat tegak karena ditopang oleh kapitalisme. Sementara birokrasi berada dalam posisi merintangi laju pertumbuhan, baik demokrasi maupun kapitalisme yang keduanya saling mendukung satu sama lain. ${ }^{12}$

Hubungan antara demokrasi dengan kapitalisme yang saling mendukung satu sama lain dapat diamati dari sejarah lahirnya kapitalisme di Eropa Barat. Kapitalisme yang bertumpu pada sistem ekonomi pasar bukan hanya memerlukan inovasi yang ekonomis dalam proses pasar, melainkan juga memerlukan perubahan hukum dan politik yang komprehensif. Perubahan hukum dan politik yang komprehensif hanya dapat terjadi apabila demokrasi ditegakkan, yakni berkenaan dengan kemerdekaan dan kebebasan perseorangan (individual) sebagai prasyarat bagi lancarnya sistem ekonomi pasar. ${ }^{13}$

Momentum historisnya, antara lain: Revolusi Perancis tahun 1789 yang menggulingkan kekuasaan feodal monarkhi-absolut, naiknya kekuasaan parlemen dan Revolusi Industri di Inggris pada abad ke-18 M.

Birokrasi menjadi dilemma bagi demokrasi karena hubungan di antara keduanya bersifat paradoks dan kontradiktif. Pada satu sisi, kekuasaan birokrasi (yang terlalu kuat) dapat menjadi ancaman bagi kelangsungan demokrasi. Namun pada lain sisi, demokrasi modern tidak akan dapat eksis tanpa dukungan birokrasi yang independen dan efisien.

11 Ibid., pp. 43-45.

${ }^{12}$ B. C. Smith (1988), Bureaucracy and Political Power, Sussex; Whearsheaf Books, pp. 25-26.

13 Robert L. Heilbroner (1982), "The Making of Economic Society" terjemahan Sutan Dianjung, Terbentuknya Masyarakat Ekonomi, Jakarta: Ghalia Indonesia, p. 85. 
Ancaman birokrasi terhadap demokrasi bisa ditinjau dari tiga alasan. Pertama, birokrasi dapat menjadi alat untuk memperkuat dominasi dan hegemoni negara yang lebih besar. Alih-alih, dalam beberapa kasus, birokrasi tampil sebagai alat represi kekuasaan negara. Kedua, birokrasi berpotensi besar melanggar otonomi, kebebasan dan privasi individual sebagai kekebalan yang merupakan esensi dari demokrasi. Ketiga, birokrasi berpotensi kuat untuk mengontrol para politisi yang dipilih oleh rakyat dan mengambil alih bidang yang seharusnya ditangani oleh politisi. ${ }^{14}$

Selain itu, birokrasi juga menyimpan potensi yang sangat besar bagi timbulnya berbagai penyimpangan dan penyalahgunaan kekuasaan, di mana salah satunya adalah korupsi. Dalil politik dari Lord Acton bahwa "kekuasaan cenderung korup, dan kekuasaan mutlak cenderung lebih korup" (power tends to corrupt, and absolute power tends to absolutely), dapat menjadi pembenaran (legitimasi) bahwa birokrasi menyimpan potensi korupsi yang sangat besar.

Sejak akhir tahun 1980-an dan awal 1990-an, bersamaan dengan arus globalisasi yang melanda hampir di seluruh dunia, berkembang semacam pengakuan bahwa sistem ekonomi yang dianggap terbaik adalah sistem pasar bebas (free-market system) sebagai bagian dari kapitalisme, sedangkan sistem politik yang dipandang terbaik adalah demokrasi. Perkembangan ini tidak dapat dilepaskan dari kemenangan kapitalisme atas komunisme, yang ditandai oleh runtuhnya Uni Sovyet sebagai simbol komunisme dan tampilnya Amerika Serikat (AS) sebagai satu-satunya polisi dunia.

Kini, AS di bawah Presiden George W. Bush merupakan 'byperpower' pertama di dunia yang menjalankan politik luar negerinya dengan ditopang oleh kekuatan militer yang belum pernah ada tandingannya dalam sejarah dunia. AS mengekspor sistem nilai mereka (Kapitalisme Pasar Bebas, Demokrasi dan HAM), menentukan negara mana yang dianggapnya beradab, rasional dan demokratis, serta mana yang manusiawi dan tidak atas dasar standar mereka sendiri. ${ }^{15}$

\section{E. Birokrasidan KorupsiMasa Kolonial}

Sejarawan Belanda, Furnivall menulis dalam bukunya, Colonial Policy and Practice: A Comparative Study of Burma and Netherlands India, bahwa negeri Belanda (Nederland) ataupun Hindia Belanda (Indonesia ketika dijajah oleh Belanda) praktis bebas dari korupsi. Pandangan Furnivall tidak sepenuhnya

14 Halevy, op. cit., p. 90.

15 'Telaah "Mari Mengubah Dunia", dalam Insani Islamic Digest, Desember (2004), pp. $20-21$. 
benar. Hindia Belanda sebelum tahun $1800 \mathrm{M}$ tatkala berada di bawah tsekuasaan VOC (Verenigde Oost Indische Compagnie) justru terdapat contoh tingkah laku korupsi yang dilakukan oleh para pegawai pemerintahan (birokrasi) VOC. Menurut Clive Day, para pegawai VOC pada umumnya menerima gaji yang terlalu rendah sehingga mudah tergoda untuk melakukan penyimpangan (korupsi). Apalagi pengawasan hampir tidak ada sama sekali. Para pejabat VOC banyak yang menjadi kaya karena mencuri (korupsi) dari perusahaan (VOC). ${ }^{16}$

Salah satu penyebab utama bangkrutnya pemerintahan (birokrasi) VOC ialah terjadinya penyalahgunaan kekuasaan dan korupsi yang merajalela. Boxer, dalam bukunya, Jan Compagnie in War and Peace 1602-1799 A Short History of the Dutch East-India Company, pada bab IV menjadikan korupsi sebagai judul bab, yakni: Runtuh Lantaran Korupsi (1741-1799). Menarik untuk diungkap bahwa para ahli sejarah masih memperdebatkan sejauh mana VOC runtuh karena korupsi, namun para jenaka masa itu "memplesetkan" VOC menjadi Vergaan Onder Corruptie yang bermakna Runtuh Lantaran Korupsi. "

Korupsi sebagai faktor utama bangkrutnya VOC terjadi, terutama disebabkan oleh gaji para pejabat, baik pejabat Belanda maupun pejabat pribumi, sangat rendah. Sebagai contoh, gaji tertinggi adalah gaji seorang gubernur jenderal sebesar 600-700 gulden per bulan, sedangkan gaji yang dianggap paling rendah adalah gaji seorang juru tulis sebesar 16-24 gulden per bulan. Semuanya menghadapi berbagai macam godaan (korupsi), namun tentu saja kesempatan terbesar untuk memenuhi godaan itu adalah gubernur jenderal. Sebagian besar gubernur jenderal setelah berhenti dari jabatannya menjadi orang yang kaya raya, dan beberapa orang malahan menjadi jutawan..$^{18}$

Untuk mendapatkan kedudukan yang strategis, para pegawai VOC terbiasa melakukan suap, sehingga mereka akan berupaya mengembalikan modal dengan menjual jabatan bupati hingga kepala desa kepada penawar yang tertinggi. Bahkan yang lebih parah, banyak pegawai VOC yang melakukan perdagangan untuk diri mereka sendiri dengan memanfaatkan VOC. ${ }^{19}$

${ }^{16}$ Lihat Theodore M. Smith (1993), "Korupsi, Tradisi dan Perubahan di Indonesia" dalam Mochtar Lubis dan James C. Scott (penyunting), Korupsi Politik, Jakarta: Yayasan Obor Indonesia, Pp. 51-52.

17 C. R. Boxer (1983), "Jan Compagnie in War and Peace 1602-1799 A Short History of the Dutch East-India Company" terjemahan Bakri Siregar, Jan Kompeni Dalam Perang dan Damai 16021799 Sebuab Sejarah Singkat tentang Persekuttuan Dagang Hindia Belanda, Jakarta: Sinar Harapan, p. 107.

${ }^{18}$ Ibid, p. 109.

${ }^{19}$ Catatan sejarah Ong Hok Ham, sebagaimana diungkap oleh Vincentia Hanny S. (2005), “Birokrasi Pelayan Bangsa Versus Pungli," dalam Harian Kompas, 1 September, p. 5. 
Memang terdapat faktor lain yang mendorong runtuhnya VOC, seperti pendapat J.C. Van Leur, sosiolog Belanda, yang melihat lemahnya angkatan laut VOC dalam hal disiplin kerja. Kelemahan ini mengakibatkan VOC tidak mampu menjaga wilayah kekuasaannya di perairan Hindia Belanda, sehingga penyelundupan dan perdagangan gelap merajalela.

Pemerintah kolonial Belanda yang mengambil alih kekuasaan VOC pascaruntuhnya VOC (1800) relatif lebih bersih meskipun pegawai yang bekerja kebanyakan adalah pegawai VOC yang korup. Namun demikian, relasi antara birokrasi dan korupsi tidak hilang. Sebagai contoh, implementasi sistem politik Tanam Paksa atau Cultuurstelsel (1830-1870) yang menggunakan sistem persentase (komisi) membuka peluang para pejabat (birokrat) pribumi untuk melakukan penyelewengan dan korupsi. Hal inilah yang dikritik oleh Douwes Dekker melalui bukunya, Max Havelaar, dengan nama samaran sang pengarang, Multatuli, yang mengkritik praktik tanam paksa sebagai kolusi antara birokrasi dan korupsi dengan ekses-ekses negatif terhadap rakyat pribumi baik berupa penindasan, kekejaman, kelaparan maupun kemiskinan.

\section{F. Birokrasidan Korupsi Masa Pascakemerdekaan}

Pascakemerdekaan, korupsi mulai merebak di Indonesia pada penghujung tahun 1950-an. Pengamatan yang dilakukan oleh Bung Hatta menunjukkan bahwa gaji para pegawai pemerintah yang tidak memadai untuk memenuhi kebutuhan meteka sehari-hari telah membuat suap dan sogok menjadi hal yang lazim. Kondisi ini menimbulkan kerusakan pada masyarakat dan negara. ${ }^{20}$

Jalinan antara birokrasi dan korupsi mencapai puncaknya pada masa rejim Orde Baru. Sentralisasi kekuasaan di tangan Presiden Soeharto pada awalnya digunakan untuk mendukung pembangunan yang cukup bermanfaat bagi rakyat. Namun dalam perkembangannya, sentralisasi itulah yang membuat Soeharto, keluarga dan para kroninya mengembangkan korupsi, kolusi dan nepotisme (KKN) sebagai prestasi terbesar rejim Orde Baru. Birokrasi menjadi rusak karena tertular oleh wabah KKN yang endemik itu. Demikian pula, adanya monopoli dalam bidang ekonomi dan industri telah membuat $\mathrm{KKN}$ semakin merajalela.

Menurut George Junus Aditjondro, KKN yang dikembangkan oleh Soeharto, keluarga dan para kroninya sebagai prestasi terbesar rejim Orde Baru serta sebagai salah satu faktor utama yang mendorong keruntuhannya dapat dilacak ke dalam delapan kelompok yayasan. Pertama, yayasan yang diketuai

${ }^{20}$ Periksa Theodore M. Smith (1993), "Korupsi, Tradisi dan Perubahan di Indonesia" dalam Mochtar Lubis dan James C. Scott (penyunting), op. cit., p. 57. 
oleh Soeharto sendiri seperti Sepersemar, Dakab, Dharmais, Amal Bakti Muslim Pancasila, dan lain sebagainya. Kedua, yayasan yang diketuai oleh Ibu Tien Soeharto semasa hidupnya seperti Harapan Kita, Kartika Candra, TMII, dan sebagainya. Ketiga, yayasan yang dikelola oleh saudara kandung, saudara tiri dan saudara sepupu Soeharto dan istrinya, seperti misalnya Probosutejo (adik tiri Soeharto) dan Sudwikatmono (saudara sepupu Soeharto). Keempat, yayasan yang diketuai oleh anak, menantu dan cucu Soeharto. Contohnya, Tutut (Tiara Indonesia, Dharma Setia, dan Tunas Harapan Timor Lorosae), Bambang Trihatmojo dan istrinya, Halimah (Bhakti Nusantara Indah), Tutut dan Halimah (Bimantara dan Bhakti Putra Bangsa). Kelima, yayasan yang diketuai oleh para besan Soeharto dan keluarga mereka seperti Kowara (Pembangunan Jawa Barat, 17 Agustus 1945) dan Soemitro Djojohadikusumo (WALHI). Keenam, yayasan yang diketuai oleh sanak saudara Soeharto dan istrinya, seperti Yayasan Mangadeg di Solo. Ketujuh, yayasan yang dikuasai oleh Soeharto melalui kaki tangannya, misal: Habibie, Bob Hasan, Sudomo, Joop Ave dan Murdiono. Kedelapan, yayasan yang dikelola ABRI tetapi sangat terlibat dalam bisnis keluarga Soeharto seperti Yayasan Kartika Eka Paksi (YKEP). ${ }^{21}$

Pascaruntuhnya rejim Orde Baru dan memasuki era Reformasi yang relatif lebih demokratis, birokrasi semakin tidak mendapatkan kepercayaan masyarakat. Hal ini sebenarnya merupakan akibat dari buruknya pelayanan birokrasi terhadap masyarakat yang sebagian besar dilakukan oleh para pegawai negeri sipil (PNS). Di samping itu, birokrasi juga tercoreng oleh KKN yang bukannya hilang melainkan bertambah merajalela. Praktik-praktik KKN seperti dalam hal pengurusan KTP, paspor dan berbagai perizinan, serta barang dan jasa yang dihasilkan oleh pihak swasta seperti jalan tol, transportasi, semen dan komoditas lainnya telah menjadi ongkos birokrasi (bureaucratic cost) yang mahal dan terjadinya distorsi dalam mekanisme pasar yang tampak pada praktik monopoli dan oligopoli yang merugikan kepentingan publik. ${ }^{22}$

Saat ini, KKN yang endemik telah merajalela bukan hanya di lingkungan birokrasi baik pusat maupun daerah melainkan juga di lingkungan legislatif baik di pusat (DPR) maupun di daerah-daerah (DPRD propinsi dan kabupaten/ kota). Bahksan, yang sangat ironis, $\mathrm{KKN}$ juga telah melanda Komisi Pemilihan

${ }^{21}$ Untuk lebih jelas dan rinci, baca George Junus Aditjondro (1998), Dari Soebarto ke Habibie Guru Kencing Berdiri, Murid Kencing Berlari: Kedua Puncak Korupsi, Kolusi, dan Nepotisme Rezim Orde Baru, Jaksarta: Masyarakat Indonesia untuk Kemanusian (MIK) dan Pijar Indonesia, Pp. 3-36.

${ }^{22}$ Lihat rubrik Fokus (2003), "Reformasi Birokrasi Butuh Rakyat yang Kritis" dalam Kompas, 6 Juli, p. 25. 
Umum (KPU), instrumen utama demokrasi yang seharusnya bersih dari perilaku buruk seperti korupsi. Perkembangan kasus korupsi di KPU menunjukkan bahwa dana KPU ternyata tidak hanya dinikmati oleh para pejabat KPU, tetapi juga turut dinikmati oleh para pejabat di Ditjen Anggaran Departemen Keuangan (diperkirakan sebesar 79.000 dollar AS dan Rp. 546 juta), serta BPK (33.791 dollar AS dan lebih dari Rp. 600 juta). ${ }^{23}$

Alhasil, reformasi birokrasi ke arah birokrasi yang menganut paradigma sebagai pelayan publik dan birokrasi yang bersih dari KKN mutlak dan sangat mendesak untuk segera dilakukan. Mengacu pada pemikiran Syafuan Rozi Soebhan, model baru birokrasi yang hendaknya dibangun di Indonesia adalah: (1) kultur dan struktur kerja yang rasional - egaliter, bukan yang irasional hirarkis; (2) hubungan kerja atas dasar partisipan - autonomus, bukan komando - intervensionis, (3) tujuan kerjanya mengarah pada pemberdayaan publik dan demokratisasi, bukan pnguasaan dan pengendalian publik; (4) sikap terhadap publik adalah professional dalam melayani publik dan transparansi biaya, bukan ekonomi biaya tinggi; (5) pola rekrutmen berdasarkan merit system, bukan spoil system; (6) model pelayanannya kompetitif, bukan kebalikannya; serta (7) keterkaitan dengan politik didasarkan pada prinsip netralitas politik birokrasi, dan bukan birokrasi yang berpolitik. ${ }^{24}$

Model birokrasi sebagaimana diungkapkan oleh Syafuan Rozi Subhan ${ }^{25}$ tersebut, dapat disimak pada tabel berikut;

\section{Model Reformasi Birokrasi untuk Indonesia}

\begin{tabular}{|c|c|c|}
\hline 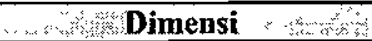 & Model Lama Birökrasi & Model Baru Birokrasi \\
\hline Kultur dan stnuktur kerja & Irasional-Hirarkis & Rasional-Egaliter \\
\hline Hubungan Kerja & Komando-Intervensionis & Partisipan - A utonomus \\
\hline Tujuan Keja & $\begin{array}{c}\text { Penguasaan, Pengendalian } \\
\text { Publik } \\
\end{array}$ & $\begin{array}{c}\text { Pemberdayaan Publik, } \\
\text { Demokratisasi }\end{array}$ \\
\hline Sikap terhadap Publik & $\begin{array}{c}\text { Rent - seeking (ekonomi } \\
\text { biaya tinggi) }\end{array}$ & $\begin{array}{c}\text { Profesional Pelayanan } \\
\text { Publik, Transparansi Biaya }\end{array}$ \\
\hline $\begin{array}{l}\text { Pola Reknitmen, Peng- } \\
\text { awasan don Penghargaan }\end{array}$ & $\begin{array}{c}\text { Spoil System } \\
\text { Nepotisme, Diskriminasi, } \\
\text { Reward atas dasar ikatan } \\
\text { Primordial - suku, ras, } \\
\text { agama) }\end{array}$ & $\begin{array}{c}\text { Merit System } \\
\text { (Pengangkatan karena } \\
\text { keahlian, pengawasan } \\
\text { kolektif, obyektif) }\end{array}$ \\
\hline Model Pelayanan & $\begin{array}{c}\text { Tidak ada kompetisi dalan } \\
\text { Pelayanan }\end{array}$ & $\begin{array}{c}\text { Kompetitif dalam } \\
\text { Memberikan Pelayanan }\end{array}$ \\
\hline Keterkaitan dengan Politik & Birokrasi Berpolitik & Netralitas Politik Birokrasi \\
\hline
\end{tabular}

${ }^{20}$ Vincentia Hanny S (2005), "Birokrasi Pelayan Bangsa versus Pungli" dalam Kompas, 1 September, p. 5.

${ }^{24}$ Syafuan Rozi Soebhan (2000), Model Reformasi Birokrasi Indonesia, PPW LIPI, tersedia di Http://www. Transparansi.or.id, p. 7.

${ }^{25} \mathrm{Ibid}$., p. 6. 


\section{G. Catatan Kepribatinan Seorang Muslim}

Semua fenomena yang telah dikemukakan di atas sungguh sangat memprihatinkan. Penulis yang nota bene seorang Muslim awam juga ikut merasa prihatin, sekurang-kurangnya karena dua alasan. Pertama, Indonesia adalah sebuah negara yang mayoritas penduduknya (sekitar $85 \%$ ) beragama Islam, sementara ajaran Islam sangat anti-korupsi. Kedua, masyarakat Indonesia dikenal sangat religius hal mana agama diperkirakan mempunyai pengaruh besar terhadap kehidupan bermasyarakat, berbangsa dan bernegara, namun dalam kenyataannya korupsi menempati ranking I di Asia.

Bahwa ajaran Islam sangat anti-korupsi dapat ditelusuri dari pemilahan lima jenis harta hasil selingkuh jabatan yang berkaitan dengan kekuasaan dan birokrasi. Kelima jenis harta yang dapat dikategorikan sebagai korupsi itu adalah sebagai berikut. Pertama, suap (risywab). Suap dan segala bentuk manifestasinya seperti uang semir, uang rokok, dan uang pelicin diharamkan dalam ajaran Islam. Semua yang terlibat dalam suap, baik pelaku, perantara maupun penerimanya dilaknat oleh Allah, sebagaimana sabda Rasulullah: "Laknat Allab bagi penyuap, penerima suap, dan perantara mereka."

Kedua, hadiah atau hibah. Dalam Islam, hadiah atau hibah yang diterima oleh pejabat atau pegawai yang terkait dengan kekuasaan dan birokrasi, merupakan salah satu bentuk kecurangan. Hal ini karena hadiah atau hibah tersebut tentu ada "udang di balik batu", yakni ada kepentingan tertentu yang melatarbelakanginya. Dalam sebuah Hadits, Rasulullah bersabda: "Pemberian (Bibab) kepada penguasa adalab kecurangan."

Ketiga, rampasan. Harta yang diperoleh dengan cara merampas atau melalui represi kekuasaan dan birokrasi mutlak diharamkan dalam Islam. Mengacu pada sabda Rasulullah: "Janganlab kamu memakan barta orang lain dengan jalan batbil."

Keempat, komisi. Semua jenis komisi, baik yang halal maupun tidak, dilarang dalam ajaran Islam untuk diterima oleh pejabat atau pegawai apabila terkait dengan kekuasaan dan kewenangan sebuah jabatan. Rasulullah mengingatkan dalam sebuah Hadits: "Siapa yang sudab diberi rezeki atas jabatannya, jangan mengambil lagi di luar itu karena berarti curang."

Kelima, rampokan. Harta yang diperoleh melalui cara kekerasan, menipu dan merugikan orang lain haram hukumnya dalam Islam. Sabda Rasulullah mengenai hal itu: "Bukan umat kami, orang yang merampas dan merampok, serta yang mendukungnya." ${ }^{26}$

${ }^{26}$ Lihat, "Pahitnya Jabatan" dalam Insani- Islamic Digest, Desember 2004, pp. 32-33. 
Pemberantasan korupsi tidak akan berarti apabila tidak ada perbaikan sistem dalam birokrasi. Sementara itu, perbaikan sistem dalam birokrasi menuntut tersedianya sumber daya manusia (SDM) birokrasi, yakni para pejabat dan pegawai, yang bersih, jujur dan bermental anti-korupsi. Di sinilah letak titik temu, di mana agama dapat berperan untuk membina dan mendidik SDM birokrasi yang bersih, jujur dan bermental anti-korupsi tersebut. Di lingkungan masyarakat Muslim, ajaran Islam yang anti-korupsi sebagaimana telah diungkap di atas mutlak perlu disosialisasikan, terutama kepada kalangan generasi muda yang nantinya akan mengisi SDM birokrasi.

Organisasi sosial-keagamaan Islam, seperti halnya Muhammadiyah dan Nahdlatul Ulama (NU), memiliki peran dan tanggung jawab yang besar dalam gerakan anti-korupsi dan pemberantasan korupsi. Keduanya memang telah bersinergi dalam gerakan anti-korupsi sejak tahun 2003, namun hasilnya belum kelihatan. Hal ini barangkali karena gerakan tersebut baru sebatas wacana, oleh karena itu perlu langkah-langkah yang merupakan aksi nyata dari kedua organisasi tersebut. Di samping itu, pemerintah juga tidak boleh tinggal diam. Diperlukan kemauan politik (political will) yang kuat dari para pemimpin bangsa ini, terutama Presiden Susilo Bambang Yudhoyono (SBY) untuk melakukan gerakan pemberantasan korupsi secara serius dan berkelanjutan. Caranya dapat diawali dengan pengawasan yang ketat terhadap para birokrat.

\section{H. Penutup}

Dari pemaparan di atas dapat ditarik beberapa simpulan sebagai berikut. Pertama, korupsi di Indonesia sebagai variabel sejarah dalam arti merupakan budaya bangsa sebenarnya tidak tepat, sebab lebih berkaitan dengan variabel struktur birokrasi yang membuka peluang dan celah-celah bagi terjadinya korupsi. Kedua, ajaran Islam sangat anti-korupsi, sehingga perlu disosialisasikan kepada seluruh masyarakat bahwa korupsi merupakan salah satu biang utama kehancuran bangsa, dan korupsi harus diberantas sampai ke akar-akarnya. 


\section{DAFTAR PUSTAKA}

Ahmad Syafii Maarif (2005), "Indonesia Baru di Tengah Pertarungan antara Mosaik Budaya yang Elok dan Kaya dengan Ancaman Keserakahan," dalam Millah, Jurnal Studi Agama, Yogyakarta: Magister Studi Islam.UII. Albrow, Martin (1996), Bureaucracy, terjemahan M. Rusli Karim dan Totok Daryanto, Birokrasi, Yogyakarta: Tiara Wacana.

Boxer, C. R (1983), “Jan Compagnie in War and Peace 1602-1799 A Short History of the Dutch East-India Company" terjemahan Bakri Siregar Jan Kompeni Dalam Perang dan Damai 1602-1799 Sebuab Sejarab Singkat tentang Persekutuan Dagang Hindia Belanda. Jalsarta: Sinar Harapan.

DjokoSusilo (editor) (2004), Kuasa antara Moral, Etika dan Amanat: Percikan Pemikiran M. Amien Rais, Yogyakarta: Palem.

Echols, John M. dan Hassan Shadily (1987). Kamus Inggris-Indonesia, Jakarta: Gramedia.

Aditjondro, George Junus (1998), Dari Soeharto ke Habibie Guru Kencing Berdiri, Murid Kencing Berlari:KeduaPuncak Korupsi, Kolusi, dan Nepotisme Rezim Orde Baru.

Jakarta: Masyarakat Indonesia untuk Kemanusian (MIK) dan Pijar Indonesia Halevy, Eva Etzioni (1983), Bureaucracy and Democracy a Political Dilemma, London: Routledge and Kegan Paul.

Hanny S, Vincentia (2005), "Melawan Korupsi 'Vis a Vis' Perlawanan Koruptor" dalam Harian Kompas, 16 Agustus.

- (2005), "Birokrasi Pelayan Bangsa Versus Pungli" dalam Harian Kompas, 1 September.

Heilbroner, Robert L (1982), "The Making of Economic Society" terjemahan Sutan Dianjung, Terbentuknya Masyarakat Ekonomi, Jakarta: Ghalia Indonesia.

Homby, A.S (1978), Oxford dvanced Learner's Dictionary of Current English, Oxford: Oxford University Press.

Insani, Islamic Digest. Desember 2004

Moeljarto Tjokrowinoto (1995), Politik Pembangunan Sebuab Analisis, Arab, dan Strategi, Yogyakarta: Tiara Wacana.

Smith, B.C (1988), Bureaucracy and Political Power, Sussex: Wheatsheaf Books. Smith, Theodore M (1993), "Korupsi, Tradisi dan Perubahan di Indonesia" dalam Mochtar Lubis dan James C. Scott (penyunting), Korupsi Politik, Jakarta: Yayasan Obor Indonesia.

Syafuan Rozi Soebhan (2000), Model Reformasi Birokrasi Indonesia, PPW LIPI, tersedia dibttp://werere.transparansior.id.

Wright, Vincent (1992), Comparative Governmentand Politics an Introduction, London: The Macmillan Press Ltd. 